Copyright (c) Gabrielle Hogan-Brun an Stefan Wolff. All rights reserved.

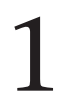

\title{
Minority Languages in Europe: An Introduction to the Current Debate
}

\author{
Gabrielle Hogan-Brun and Stefan Wolff
}

The use of the language of choice is an important human right as it is through language - a primary marker of identity - that we are able to identify ourselves, others, and to be identified by others, that we think, communicate and generally relate to the world around us. The violation of this right bears a potential for conflict as is only too evident in many ethnic conflicts in Europe, Africa and Asia, where language rights are often among the demands behind which ethnic groups rally when they challenge states for a recognition of their distinct identities. Acknowledging this potential for conflict has generated a long history of specific rights afforded to linguistically defined minority communities in Europe. The Peace Treaty of Westphalia, the Final Act of the Congress of Vienna and the League of Nations Minority Treaties during the inter-war period in the first half of the twentieth century all included provisions for specific group-based rights in key areas related to language use, such as cultural institutions, education and communication with public services. In the post-1945 period, the new international system took a turn away from group rights and focussed on individual human rights. The Charter of the United Nations, the Universal Declaration on Human Rights, the International Covenant on Civil and Political Rights (ICCPR) and the European Charter of Human Rights (see references) all refer to language as an important human right, but in their focus 
Copyright (c) Gabrielle Hogan-Brun an Stefan Wolff. All rights reserved.

\section{Gabrielle Hogan-Brun and Stefan Wolff}

on the individual, they provide less protection for languages that are only used by small groups within larger states. In Europe, these shortcomings have been recognized, and the period since the end of the Cold War has seen a reorientation towards group rights, not to replace, but to complement individual human rights: the Copenhagen Document of the Conference on Security and Cooperation in Europe, the Framework Convention for the Protection of National Minorities and the European Charter for Regional or Minority Languages (ECRML) (see references) are all evidence of that trend. Although it explicitly excludes the languages of immigrant communities, the latter is particularly important in that it is the first legally binding document for the protection of minority languages and clearly states the areas in which states have an obligation to take action on behalf of speakers of minority languages. These include education, communication with authorities, public services, media, culture, economic and social life and transfrontier exchanges. What is significant about these and other similar documents, regardless of whether they are of a legally binding nature, is that they set standards and define practice, and that they give expression to a norm according to which it is no longer acceptable to suppress minority languages actively or simply by neglect. Yet, the existence of such norms and standards does not automatically mean that they are immediately embraced by every national government and incorporated into national law and policy. On the contrary, politicians frequently proclaim their support for the protection and support of minorities in general, but may not recognize the need or applicability of a particular issue to their own country. For example, France, upon signing the ECRML deposited a lengthy declaration with the Council of Europe (COE), stating, amongst other things, that '[i]n so far as the aim of the Charter is not to recognize or protect minorities but to promote the European language heritage, and as the use of the term "groups" of speakers does not grant collective rights to speakers of regional or minority languages, the French Government interprets this instrument in a manner compatible with the Preamble to the Constitution, which ensures the equality of all citizens before the law and recognizes only the French people, composed of all citizens, without distinction as to origin, race or religion.' In other words, France does not recognize the existence of minority languages in its territory. Likewise, Croatia declared that 'the provisions of Article 7, paragraph 5, of the Charter 
Copyright (c) Gabrielle Hogan-Brun an Stefan Wolff. All rights reserved.

shall not apply', that is the country does not extend the provisions made for regional languages to non-territorial languages, which primarily affects Romani. ${ }^{1}$ With regard to the Framework Convention on the Protection of National Minorities, it was the inability (and unwillingness) of the contracting parties to reach a consensus on the definition of 'national minority' that subsequently gave signatory states a wide margin for interpretation, that is to deliberately exclude certain groups from the relevant provisions. Estonia, for example, noted in its signature document in 1997 that it defined a national minority as 'those citizens of Estonia who reside on the territory of Estonia; maintain longstanding, firm and lasting ties with Estonia ..., thereby circumventing the tricky issue of its large non-citizen Russian-speaking population. ${ }^{2}$

Interpretations and adaptations to specific national circumstances to one side, another and equally important question that also concerns states that incorporate international norms and standards in full into their national legislation is whether adequate language rights alone are enough to create conditions in which language minorities can express, preserve and develop their distinct identities. In the light of recent experience, the obvious answer to this question is that what is needed is 'language rights plus', and the 'plus' has to be an important component of any discussion about how to translate policy into practice both in the narrower context of language rights and in the wider one of human and minority rights. There are three main reasons for this. First, language policy alone that aims to modify the linguistic environment at a societal level is unlikely to be sufficient to give ethnic minorities the opportunity to preserve their identity, or in some cases even their language. Second, misunderstanding the role of language policy can easily lead to frustrations and tensions, exacerbating already volatile situations. A low economic and social status of a minority language can make it unattractive to learn and to retain through the generations, especially when it is seen as an impediment for upward social mobility. Furthermore, without opportunities to participate in public life as members of a particular language minority, the right to use one's mother tongue can become meaningless, and the language may degrade to a (dys-)functional variety usable only in limited, private contexts. Research on the economics of language and ethnicity has highlighted the relationship between language and labour, which goes some way 
Copyright (c) Gabrielle Hogan-Brun an Stefan Wolff. All rights reserved.

\section{Gabrielle Hogan-Brun and Stefan Wolff}

to explain current developments in language planning (Grin and Villaincourt 1999).

However, and this relates to possible misjudgements of the role that language rights can play in a situation of more generally tense inter-ethnic relations, history has shown that more liberal language policies have not always been an appropriate mechanism to resolve the far more complex conflict situations involving ethnic minorities - it can be 'too little, too late' for an aggrieved minority to have its demands for language rights accommodated, but too much for a majority that feels threatened by such an assertion of identity on the part of a minority. The escalation of the conflict between ethnic Albanians and ethnic Macedonians in the Republic of Macedonia in 2000 is evidence of this dilemma, as is the situation in the Romanian province of Transylvania. In both cases, language minorities (Albanians in Macedonia, Hungarians in Romania) demanded the creation of a university that taught its courses in their native tongue. Rejection of this demand quickly led to an escalation of tensions; in the case of Macedonia it even led to a short civil war like violent conflict. Both situations were eventually resolved, but not without initial escalations of inter-ethnic tensions.

Language rights and language policy, therefore, are two important aspects within a wider framework of minority protection, and only if this framework is right, will it be possible to put the conditions in place in which language minorities can preserve their language as part of their identity, if they so wish. That is, members of minorities should be able to make a choice, individually and collectively, about how important a component their language is for their identity. Thus, while the protection of a minority language may not be the most important criterion for the preservation of a minority identity, its forced absence will leave a void in this identity with consequences not just for the individual, but also for society as a whole.

\section{II}

Over the past few years, the European Union (EU) has become an important forum for language minorities to articulate their demands. Whilst in the past their position had been marginalized in most European states, the EU's commitment to linguistic pluralism has had a beneficial effect for many (autochthonous) minority communities. 
Copyright (c) Gabrielle Hogan-Brun an Stefan Wolff. All rights reserved.

Minority Languages in Europe: An Introduction

Despite such improvements in some European states, the relationship between democracy and language policies aimed at accommodating linguistic diversity in multilingual countries remains complex. The uniqueness of each minority situation requires that language planning be conducted jointly by government institutions, minority representatives and a wide range of other formal and informal stakeholders, including civil society and pressure groups. It is important to bear in mind that decisions affecting the policy domains of status and corpus planning, language standardization and management of language use can be made according to a wide variety of considerations, including ideology, identity, image or human and minority rights concerns, as well as a variety of economic factors. Against the background of such realities, an analysis of language policy always needs to focus on who formulates and implements specific policies and in whose interest they are. In other words, language policy is not made in a vacuum of normative aspirations, but in a concrete context in which different actors with often diverse interest and opportunity structures interact.

\section{III}

Taking these complex realities as a given and as its starting point, the aim of this collection is to examine how language policy has developed in different, and often changing, social, legal and political frameworks in Europe. Our aim is to be both descriptive and prescriptive; that is, in the chapters that follow our contributors analyse what is, assess the shortcomings of legislation and policy, and, where appropriate, make recommendations as to how language policy and/or the context in which it happens needs to be improved in order to accommodate and support linguistic and cultural diversity in different countries in which language minorities exist and articulate their demands. Throughout the volume, we use the term 'minority languages' to describe numerically inferior groups of people who speak a language different from that of the majority of a given country (i.e. the state or official language), are in a non-dominant political position, and, to some extent, seek to preserve their distinct linguistic identity (often as part of a wider ethno-cultural identity). We base this term on factual criteria, that is, a minority language in one state (such as Russian in Estonia) may constitute a majority 
Copyright (c) Gabrielle Hogan-Brun an Stefan Wolff. All rights reserved.

\section{Gabrielle Hogan-Brun and Stefan Wolff}

language in another country (i.e. Russia). Minority languages may also include speakers of globally not widely used languages as is the case for instance with speakers of Welsh in Wales.

The first set of contributions focuses on different social, political and legal structures that determine the context in which language policy is formulated and implemented. Camille O'Reilly opens the discussion with an analysis of the significance that language has in the context of identity politics, reminding us to avoid oversimplification when dealing with the links between language and culture and arguing that even when language is 'just symbolic' it can play a key role in understanding the dynamics of conflict. The symbolic importance, which Gaelic still is found to have in Ireland, shows that language can figure as a highly salient feature of cultural differences and that it can become an important symbol of ethnic identity. Similarly, the Deaf community, who does not define itself on audiological criteria as do hearing people, are progressively expressing their (self-constructed) identity. Their drive for empowerment and increasing recognition of the right to self-ownership has led to a redefinition of identity on their part. Romani too has helped shape the identity of the Roma population but has not been an instrumental factor in creating political consensus amongst its speakers. The fragmentation of former Yugoslavia on the other hand exemplifies how ethnic boundaries and cultural differences may lie dormant for decades only to be reactivated as proof that it has become impossible for two groups to coexist. There had been peace between Serbs and Croats since 1945, and Serbo-Croat was considered to be one language. The main cultural differences were that they practise different variants of Christianity and that they use different scripts (the Orthodox Serbs follow the Cyrillic alphabet, while the Catholic Croats use the Latin script). But as the national borders between these new states solidified, their languages and other aspects of culture became more distinctive too on the basis of identity politics and policies of segregation. The symbolic aspect of ethnicity had hence been pivotal in the process of social exclusion/inclusion as attachment and loyalty to new nations were being created.

With reference to the disputed status of Ulster Scots in Northern Ireland, Mairéad Nic Craith then explores the political relevance of the ECRML for the non-official languages of Europe. The main aims of this 1992 Charter are the protection of regional and minority 
Copyright (c) Gabrielle Hogan-Brun an Stefan Wolff. All rights reserved.

languages and the promotion of a series of concrete measures to help a language survive. These measures involve domains such as education, public services, media, administration, legal authority and the law, cultural facilities and activities, economic and social activities and trans-frontier exchanges. The Charter's impact is restricted in the sense that there is no common judicial framework to control its application in the member states which have ratified all parts of it. In her view the Charter, whose role is confined to autochthonous languages, has the potential to serve as a catalyst for the re-definition of some dialects as languages, as in the case of Ulster Scots, which was subsequently included in the Charter, along with Scots in Scotland. In this context, the revival of minority languages and their revitalization as community languages can be perceived as a political strategy within a new framework, in which nation-states no longer function as the main point of reference for their definition.

John Packer provides insights into the role played by the High Commissioner on National Minorities (HCNM) of the Organisation for Security and Co-operation in Europe (OSCE) in trying to secure conditions conducive to the preservation and free use of minority languages and for the equality of persons belonging to linguistic minorities. Established in 1992 as an instrument of 'conflict prevention at the earliest possible stage', the HCNM has played a crucial role in reducing inter-ethnic tensions in potentially explosive situations in a number of Central and Eastern European countries. The main instrument in that has been the issuing of recommendations, which can be either country-specific or relate to more general matters in facilitating peaceful inter-ethnic relations. In the context of our volume, the Oslo Recommendations on the Linguistic Rights of National Minorities of February 1998 are particularly valuable, as they have contributed to the earlier mentioned process of setting international standards and norms on the protection and promotion of minority languages. ${ }^{3}$

Taking an international law perspective, Kristin Henrard examines language rights as part of a comprehensive and adequate system of minority protection. Her assessment of individual human and minority rights standards reveals that, while both are important for the language rights of population groups in multinational societies, a qualified recognition of the right to self-determination for minorities is essential to improve the integration, but not (forced) assimilation, 
Copyright (c) Gabrielle Hogan-Brun an Stefan Wolff. All rights reserved.

of language minorities into the social, economic and political structures of the countries in which they live.

As the second set of contributions shows, such a qualified recognition of the right to self-determination can manifest itself in many different ways - from basic non-discrimination provisions in constitutions to complex federal and autonomy regimes. Trends within Western Europe generally point in the latter direction. For example, Belgium, Italy and the United Kingdom all have systems of territorial organization in place which give far-reaching powers to different, and often ethnically or otherwise distinct parts of the population, allowing them to manage a wide range of issues, including areas that are of particular importance to the protection, expression and development of minority languages, such as education and culture. A similar situation exists in Spain, where, apart from Castilian, three other major languages are spoken - Catalan, Basque and Galician. While they share equal status with Castilian as official languages in the relevant autonomous areas, Spain nevertheless presents itself officially as a monolingual state with Castilian as the only official state language. The changed status of Spain's 'other' languages since devolution in 1978 has resulted in standardization and modernization processes to adapt these languages to an expanded set of social functions (Bastardas 1995: 21-2). It is in this context that Carmen MillánVarela examines the ambiguous role of translation activities which she identifies as crucial tools in the (re-)construction and development of national languages and literatures. Her analysis leads her to call for better planning in translation activities in order to increase social domains in which they can be used, to create and consolidate registers and to contribute to the normalization of a (minority) language.

With few exceptions, such as some of the successor states of the Soviet Union, the territorial accommodation of minority rights is not the dominant trend in how states in Central and Eastern Europe deal with actual or potential ethnic conflict. Since 1989 the region has been rife with nationalist tension, often, but not exclusively linked to language issues. With the establishment of new states, language differences have been used in the creation of abstand (distance) and ausbau (elaboration) languages in the struggle for an unambiguous national identity. The importance of a language as a core component of national identity and the consequent need of corpus planning is 


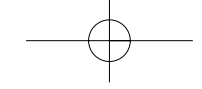

Copyright (c) Gabrielle Hogan-Brun an Stefan Wolff. All rights reserved.

the topic of the contribution by Vanessa Pupavac. She illustrates how language debates in the post-Yugoslav states are not linguistically but politically motivated to legitimize political claims. Following the fragmentation of the Yugoslav federation, the demise of a shared Serbo-Croat language and its multiplication into four separate languages - Bosnian, Croatian, Serbian and Montenegrin - has been intimately bound up with the state of majority-minority relations in this part of Southeastern Europe. In Croatia, for example, a situation has thus been created in which the insistence on minority rights for the country's Serb population (whose members have been singled out as members of an aggressor nation) is inappropriate to address current local needs.

The rationale of language legislation in newly independent states cannot but be closely linked to the goals of nation-state building. In the Baltic Republics, where independence has been achieved for a second time in the twentieth century, multinational polities had evolved as a result of Soviet internal migration policies. Consequently, language policy has been high on national and international agendas, and with the advancement of democratization, the management of language diversity has emerged as a principal issue. In her contribution, Gabrielle Hogan-Brun examines evolving language dynamics in the Baltic Republics since the restoration of independence in 1990. Conflicts over language and citizenship issues persist, particularly in Latvia and Estonia, where Russian-speaking language minorities form large parts of the resident population. Whilst Western monitoring has had an impact on existing policies, it is argued that legal advice needs to continually take account of local re-adjustments to past injustices.

In a comparative analysis of legislative and policy frameworks in Hungary, Poland and Romania, Karl Cordell and Stefan Wolff examine the situation of German language minorities in these three countries. Having lived in their homelands for hundreds of years, the twentieth century marked a sharp turn away from the previous, relatively peaceful coexistence with other ethnic minorities and majorities. German warfare and occupation policy in two world wars coupled with anti-German discrimination on the part of the three states in the interwar and Cold War periods meant that relations between ethnic Germans and other minority and majority communities deteriorated to such an extent that assimilation (Hungary) or 
Copyright (c) Gabrielle Hogan-Brun an Stefan Wolff. All rights reserved.

\section{Gabrielle Hogan-Brun and Stefan Wolff}

emigration (Romania and Poland) seemed the only realistic ways for members of German language minorities to cope with their predicament. Analyzing developments in minority policy in all three countries, the authors conclude that the many positive changes that occurred here after the fall of communism, for the most part, came too late to revitalize and consolidate functioning community structures that would have been necessary to secure the long-term survival of German language minorities, in the sense of German remaining, or being restored, as a fully functional minority language.

Apart from the study of specific, often territorially concentrated national language minorities (i.e. communities who have a kin-state, in which their mother tongue is the official language), another and equally important dimension in the analysis of the situation of language minorities in Europe is the protection of non-territorial communities. The Roma, Europe's largest and fastest growing ethnic minority - estimated to have between six and 12 million members share a common history and language. A scattered community, they are politically, economically and culturally marginalized and ethnically stigmatized. Originated in the Indian subcontinent, most of them are settled in Eastern Europe, where they are still seen as secondclass citizens. Along with respect for minority rights in general, their treatment has been a central issue in the process of EU enlargement. In his analysis, Dieter Halwachs points out that, whilst the Romani language generally enjoys a low prestige and the relationship with the contact languages has never been one between equals, its internal and external status have recently improved. As a result, moderate official attention has been attributed to Romani as a European minority language, and it has been granted official minority status in Austria.

In contrast to the widespread interest that ethnic language minorities have received over the past decade in East and West, national and international policies have to date only made a limited impact on the recognition and development of sign languages. An estimated 320,000 Deaf Europeans use sign languages, a visual-spatial, natural set of languages which has developed independently of spoken tongues. Many Deaf people are bilingual, using sign language for conversation whilst being fully literate in a majority language. There is no written form, which may in the past have distracted from a move towards official recognition of its status when compared to other minority languages with a literary tradition. The linguistic 
Copyright (c) Gabrielle Hogan-Brun an Stefan Wolff. All rights reserved.

rights and needs of the Deaf communities are arguably also a minority rights issue, as these are groups with a claim to a distinct cultural identity. On 19 November 1988, the European Parliament resolved that member states should grant their indigenous sign languages equivalent status to that of the national spoken languages. By 1998, Denmark, Finland, Sweden and Portugal had afforded some degree of official acknowledgement to their indigenous sign languages, and this process is under way in the Netherlands. The British Deaf community has sought recognition under the ECRML, with limited progress so far (Woll 2001). In his chapter, Graham H. Turner pinpoints the Deaf community's primary requirement of enactment policies that give due recognition to the ongoing significance of British Sign Language within the signing community. Highlighting their claims to the status of a cultural and ethnic group, he traces how the Deaf have fought to cast off their identification as disabled, and introduces arguments that have been put forward for treating sign languages like any other minority language within the EU. In his view, democratic institutions should provide mechanisms for effective recognition and representation of distinct voices and perspectives, allowing for the self-organization of group members that could lead to collective empowerment.

In the concluding chapter of this volume, Stephen May examines the links between nationalism, language and democracy in Europe. Focussing on legitimation and institutionalization, he argues that an effective challenge of the idea of cultural and linguistic homogeneity can only be mounted when the origins and developments of today's dominant languages and language ideologies are properly understood. Legitimation and institutionalization, among other things, May contends, have enabled some languages to become official, national, state languages, whereas others, deprived of legitimation and institutionalization, have become marginalized, minority languages often struggling for their very survival in the face of the greater national functionality of majority languages and the greater global appeal of English. These difficulties notwithstanding, May also points to several positive developments and new opportunities for minority languages to share in a similar degree of legitimation and institutionalization that has been afforded to national languages, which have arisen in the context of both higher levels of supranational integration in the $\mathrm{EU}$ as well as through the parallel 
Copyright (c) Gabrielle Hogan-Brun an Stefan Wolff. All rights reserved.

\section{Gabrielle Hogan-Brun and Stefan Wolff}

and closely related processes of devolution. As May points out with reference to the case of Catalan, increasing the levels of selfgovernance for minorities, gives them enhanced opportunities for the legitimation and institutionalization of their mother tongue. However, the very processes that historically led to the dominance of today's national languages are often perceived as discriminatory by speakers of majority languages when applied to minority languages.

This implies a fundamental point that is relevant to all the contributions in this volume: perceptions of individual speakers of both minority and majority languages as to the status of their own and other languages play a crucial role in determining the prospects of the future of minority languages. While majority languages hardly need to worry about the status their language has in society, speakers of minority languages are often in a completely different, far less advantageous position, having to make difficult choices between functionality and social mobility, on the one side, and preserving the cultural heritage of their community, on the other. However, the debate among academics and policy makers has since long moved beyond this stark choice. Linguistic rights of national minorities (but not yet those of immigrant communities, with which we are not concerned in this volume) have become key elements in a much broader set of legal and policy tools to enable speakers of minority languages to be recognized and treated as equal members of societies. From this perspective, it is also important to acknowledge that the maintenance of language diversity is a task for society as a whole, not just for a handful of minority language speakers and activists. To make a contribution to this effort is one of the tasks that the editors and contributors hope to achieve with this volume.

\section{Notes}

1. For the full text of these and further reservations and declarations, see http://conventions.coe.int/Treaty/EN/DeclareList.asp?NT=148 and CM=1 and $\mathrm{DF}=10 / 02 / 03$.

2. For the full text of this and further reservations and declarations, see http://conventions.coe.int/Treaty/EN/DeclareList.asp?NT=157 and CM=1 and $\mathrm{DF}=10 / 02 / 03$.

3. For an overview of all country-specific and general recommendations of the HCNM, see http://www.osce.org/hcnm/documents/recommendations/ 
Copyright (c) Gabrielle Hogan-Brun an Stefan Wolff. All rights reserved.

Minority Languages in Europe: An Introduction

15

\section{References}

\section{Official documents}

Charter of the United Nations, http://www.un.org/aboutun/charter/index.html

Document of the Copenhagen Meeting of the Conference on the Human Dimension of the CSCE, http://www.osce.org/docs/english/1990-1999/ hd/cope90e.htm

European Charter for Regional or Minority Languages, http://conventions. coe.int/Treaty/EN/WhatYouWant.asp?NT $=148$ and $\mathrm{CM}=1$ and $\mathrm{DF}=10 / 02 / 03$

European Convention on Human Rights, http://www.un.org/aboutun/ charter/index.html

Framework Convention for the Protection of National Minorities, http://conventions.coe.int/Treaty/EN/WhatYouWant.asp?NT=157 and $\mathrm{CM}=1$ and $\mathrm{DF}=10 / 02 / 03$

International Covenant on Civil and Political Rights, http://www.unhchr.ch/ $\mathrm{html} / \mathrm{menu} 3 / \mathrm{b} / \mathrm{a} \_\mathrm{ccpr} . \mathrm{htm}$

The Oslo Recommendations Regarding the Linguistic Rights of National Minorities, http://www.osce.org/hcnm/documents/recommendations/oslo/ index.php3

Universal Declaration of Human Rights, http://www.un.org/Overview/ rights.html

\section{Secondary sources}

Bastardas, A., 1995, Language Management and Language Behaviour Change: Policies and Social Persistence, Catalan Review, 9(2): 15-38.

Grin, F. and F. Villaincourt, 1999, The Cost-Effectiveness Evaluation of Minority Language Policies. Case Studies On Wales, Ireland And The Basque Country. Flensburg, European Centre for Minority Issues (ECMI), Monograph \#2.

Woll, B., 2001, The Unheard Languages of Europe. Policy into Practice for Lesser used Languages in Europe. A paper presented at the British Council conference 'Policy into Practice for Lesser used Languages in Europe.' Hilton Hotel, Cardiff, 30 September-5 October 2001. 